\title{
«Cahiers Mérimée» 9
}

\section{Michel Arrous}

\section{(2) OpenEdition \\ Journals}

\section{Édition électronique}

URL : http://journals.openedition.org/studifrancesi/15562

DOI : 10.4000/studifrancesi. 15562

ISSN : 2427-5856

\section{Éditeur}

Rosenberg \& Sellier

\section{Édition imprimée}

Date de publication : 1 décembre 2018

Pagination : 506-507

ISSN : 0039-2944

\section{Référence électronique}

Michel Arrous, « «Cahiers Mérimée» 9 », Studi Francesi [En ligne], 186 (LXII | III) | 2018, mis en ligne le 01 janvier 2019, consulté le 06 janvier 2021. URL : http://journals.openedition.org/studifrancesi/15562 ; DOI : https://doi.org/10.4000/studifrancesi. 15562

Ce document a été généré automatiquement le 6 janvier 2021.

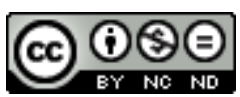

Studi Francesi è distribuita con Licenza Creative Commons Attribuzione - Non commerciale - Non opere derivate 4.0 Internazionale. 


\title{
«Cahiers Mérimée» 9
}

\author{
Michel Arrous
}

\section{RÉFÉRENCE}

«Cahiers Mérimée» 9, Paris, Classiques Garnier, 2017, 199 pp.

1 Cette livraison rassemble sept études en tous points remarquables parce qu'elles renouvellent ou approfondissent l'approche d'œuvres privilégiées par la critique et d'autres qui le sont moins. Alors que la mystification et le pastiche dans La Guzla (1827) ont fait l'objet de nombreuses recherches, on s'est moins préoccupé du rapport que la poésie illyrique de «M. Première Prose» avec le devenir de la poésie d'inspiration épique (pp. 9-30), Sylvie THOREL, après avoir rappelé que cette œuvre est le premier recueil de «petits poèmes en prose» de la littérature française, montre que Mérimée - séduit par les poésies étrangères («romances du Cid», ballades apocryphes de Macpherson, poésie populaire européenne, particulièrement de l'Europe centrale)-s'inscrit dans le mouvement folkloriste tout en réfléchissant au renouvellement poétique. Dans Un peintre anglais au Salon de 1839. Mérimée, critique d'art (pp. 31-54), Christophe LONGBOISCANIL évoque les conceptions esthétiques du salonnier dont le discours implique une théorie de l'art - dans ses grandes lignes, c'est celle de Quatremère de Quincy, d'ailleurs trop rapidement mentionné - reposant sur le principe de vraisemblance et de véracité. Si Mérimée, prudemment, se garde de prendre parti pour ou contre Delacroix, il juge ses toiles faibles dans l'expression et le dessin, et trop brutal l'usage de la couleur. En revanche, toute son admiration va à Decamps, quoiqu'il relève par endroits une imitation insuffisante. Dans ses goûts et ses choix (par exemple H. Vernet...) Mérimée se montre fidèle aux conceptions classiques de la peinture, celles de son père et des théoriciens contemporains. Les préventions de Mérimée à l'égard de l'esthétique romantique, François GÉAL les retrouve dans un cas paradoxal (Mérimée/Goya, chronique d'un désamour annoncé, pp. 55-90). Alors que le peintre aragonais a été l'objet en France d'un véritable engouement, Mérimée a manifesté de la gêne à son égard, dès l'époque des Lettres d'Espagne, gêne qui se transformera par la suite en un rejet total, comme on peut le voir dans des lettres à Mme de Montijo et à la duchesse Colonna. Ce que 
Mérimée, admirateur de David et d'Ingres, reproche à Goya (mais aussi à Murillo et Valdès Leal), c'est la laideur ou l'excès de ressemblance, c'est de ne pas avoir respecté le principe classique («savoir choisir dans la nature»). À l'approche des relations entre Mérimée et Jaubert de Passa, en partie déjà documentée par J. Saquer, Marie-Hélène SANGLA apporte de riches compléments grâce à l'inventaire en cours des archives longtemps conservées au Monastir del Camp où l'Inspecteur général séjourna en novembre 1834 (La correspondance de Prosper Mérimée et de François Jaubert de Passa (1835-1855), pp. 91-106). Dans l'état actuel du fonds, on dénombre 21 lettres échangées entre les deux érudits devenus amis, dont deux inédites. L'influence déterminante de Jaubert est rappelée, ainsi que les emprunts que Mérimée lui a faits pour ses Notes d'un voyage dans le Midi. Thierry OzWALD aborde cette «forme latérale de la critique» (Borges) qu'est la préface. L'art de la préface, voire de la postface, est chez Mérimée une pratique souvent trop rapidement évoquée (Question de principe ou attrape-nigaud. L'écriture préfacielle selon Mérimée, pp. 107-129). Expert sinon virtuose, Mérimée recourt à trois types de préfaces: dans le premier, celui des essais historiques, il s'agit, conformément à la tradition, d'expliquer, de préciser ou de justifier; dans le second, on a affaire à un piège (Clara Gazul, La Guzla, La Famille de Carvajal); dans le troisième, la préface sert à identifier et magnifier certains maîtres. Dans les préfaces aux essais se dessinent les linéaments de l'anthropologie mériméenne; dans celles des œuvres littéraires, connues pour leurs jeux de masques, l'auteur joue à piéger le lecteur; on quitte la parodie avec les préfaces à des œuvres d'auteurs du xvi siècle (Cervantès, Brantôme, d'Aubigné) ou contemporains (Tourguéniev, Stendhal, Jacquemont). Aucune d'entre elles n'est un manifeste ni un plaidoyer. Sans doute aurait-il fallu examiner plus avant la rhétorique mise en œuvre par Mérimée quand il invite son lecteur à le suivre. Serigne SEYE a choisi, après J. Sob et $\mathrm{D}$. Dabla, un cas étonnant de reprise intertextuelle en 1981 ("Le Temps de Tamango" de Boubacar Boris Diop. Une réécriture postcoloniale d'une nouvelle de Mérimée, pp. 131-146). L'écrivain sénégalais reprend la diégèse de la nouvelle tout en introduisant de notables différences dans le système spatio-temporel, les personnages, la conduite du récit et les procédés esthétiques. La première différence réside dans la réhabilitation de Tamango (il se libère, reprend son épouse, contrôle le bateau et ramène à bon port tous les noirs); la seconde dans les choix esthétiques de Diop qui l'éloignent de son modèle, quoique l'intrigue de Mérimée ne soit pas perdue de vue. Tout cela doublé par le discours idéologique propre à la littérature postcoloniale qui remet en cause l'hégémonie européenne et, dans le cas de Diop, la soumission du héros de Mérimée. Autre forme de transposition avec l'adaptation cinématographique dont Philippe MET a choisi deux exemples symétriquement inverses (Le fantastique mériméen à l'écran. "Lokis", de Majewski à Borowczyk, pp. 147-165). Dans l'ensemble fidèle au récit source et soucieux de la couleur locale, mais sans s'interdire quelques adjonctions qui ne trahissent pas le climat de la nouvelle, Majewski donne à son Lokis (1970) l'allure d'un récit gothique, d'où de notables déviations; Borowczyk, connu pour ses adaptations d'histoires libertines et érotico-pornographiques, propose avec La Bête (1975), dont est donné le synopsis, un «radical changement d'optique et de registre» puisqu'il privilégie le substrat libidinal et le refoulé archaïque. À titre de comparaison, l'auteur prolonge opportunément sa réflexion en abordant quelques-unes des adaptations de La Vénus d'Ille, par Majewski (1969) et Mario Brava (1979), sans oublier le projet avorté de Cocteau en 1942. Marie CALVEZ, qui continue la publication de lettres inédites de Mérimée au ministre Fould, présente et commente une lettre de 1860 où il est question du bien-fondé de la présence de collections d'antiques à la Bibliothèque 
impériale (pp.173-176). Figurent en fin de volume un long et scrupuleux examen par Alexandre zVIGUiLsKY de la récente édition des Études et traductions de littérature russe (pp. 179-185), ainsi que la continuation jusqu'en 2015 de la «Bibliographie de la critique sur l'œuvre littéraire et historique de Mérimée», par Xavier BOURDENET (pp. 189-195). 